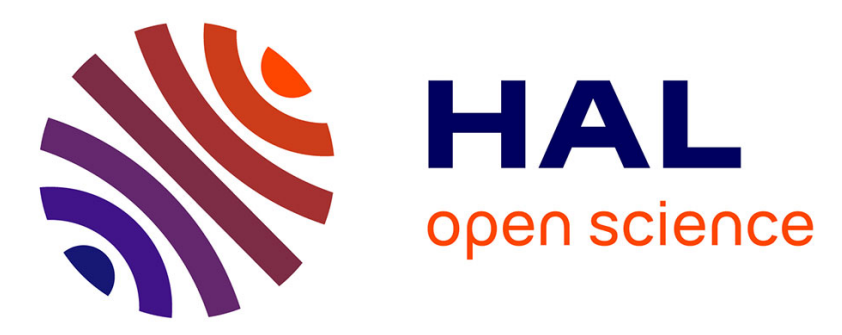

\title{
Pacemaker endocarditis caused by Propionibacterium acnes: A case report
}

\author{
Warren Noel, Nadjib Hammoudi, Elzbieta Wegorowska, Cossimo \\ d'Alessandro, Olivier Steichen
}

\section{To cite this version:}

Warren Noel, Nadjib Hammoudi, Elzbieta Wegorowska, Cossimo d'Alessandro, Olivier Steichen. Pacemaker endocarditis caused by Propionibacterium acnes: A case report. Heart \& Lung, 2012, 41 (6), pp.e21-23. 10.1016/j.hrtlng.2012.04.006 . hal-01172591

\section{HAL Id: hal-01172591 \\ https://hal.sorbonne-universite.fr/hal-01172591}

Submitted on 7 Jul 2015

HAL is a multi-disciplinary open access archive for the deposit and dissemination of scientific research documents, whether they are published or not. The documents may come from teaching and research institutions in France or abroad, or from public or private research centers.
L'archive ouverte pluridisciplinaire HAL, est destinée au dépôt et à la diffusion de documents scientifiques de niveau recherche, publiés ou non, émanant des établissements d'enseignement et de recherche français ou étrangers, des laboratoires publics ou privés. 


\section{Pacemaker endocarditis caused by Propionibacterium acnes: a case report}

Warren Noel, MD ${ }^{1}$, Nadjib Hammoudi, $\mathrm{MD}^{2}$, Elzbieta Wegorowska, MD ${ }^{1,3}$, Cossimo $\mathrm{D}^{\prime}$ Alessandro, $\mathrm{MD}^{4}$, Olivier Steichen, $\mathrm{MD}^{1,3}$

${ }^{1}$ AP-HP, hôpital Tenon, internal medicine department, Paris;

${ }^{2}$ AP-HP, hôpital Pitié Salpétrière, cardiology department, Paris;

${ }^{3}$ Université Pierre et Marie Curie - Paris6, faculty of medicine, Paris;

${ }^{4}$ AP-HP, hôpital Pitié Salpétrière, cardiovascular surgery department, Paris.

Corresponding author: Olivier Steichen

Service de Médecine Interne, Hôpital Tenon,

4 rue de la Chine F-75020 Paris, France

Email: olivier.steichen@tnn.aphp.fr

Tel. +33156017831 


\begin{abstract}
A 74-year old man, with a permanent pacemaker placed 2 years ago for high grade atrioventricular block, was admitted for worsening fatigue, confusion and thrombocytopenic purpura without fever. White blood cell count and C-reactive protein were elevated and echocardiography revealed a $6 \times 3 \mathrm{~cm}$ echogenic mass surrounding the pacemaker leads. Multiple blood cultures were performed and one bottle only grew Propionibacterium acnes at 93 hours. The patient underwent surgery and 16S rRNA gene PCR amplification confirmed the presence of $P$. acnes in the removed vegetation.

Patients with late onset device-related endocarditis often present with vague symptoms and fever may be absent, obscuring the clinical diagnosis. Blood cultures and transesophageal echocardiography are key diagnostic tests. As a slow-growing, low virulent and common human skin germ, P. acnes can be wrongly considered as a blood culture contaminant.
\end{abstract}

Key words: Propionibacterium; artificial pacemaker; bacterial endocarditis; prosthesis related infection.

\author{
Abbreviations: \\ CIED: Cardiovascular implantable electronic device \\ CRP: C-Reactive Protein \\ CT: computed tomography \\ PCR: polymerase chain reaction
}




\section{INTRODUCTION}

Propionibacterium acnes is a slow growing anaerobic gram-positive bacillus that belongs to the human cutaneous flora. Despite its low virulence, it can cause various life-threatening infections including brain abcesses, spondylodiscitis, endophtalmitis and bone infections. ${ }^{1}$ Infective endocarditis have been reported, typically late post-operative prosthetic valve infections. ${ }^{2}$ When $P$. acnes is isolated in blood cultures, it can be wrongly regarded as a skin contaminant. We report a case that illustrates the diagnostic challenges of pacemaker-related endocarditis due to P. acnes.

\section{CASE REPORT}

A 74-year old man was admitted because of worsening fatigue for 15 days. He had a history of type 2 diabetes and hypertension, and a pacemaker was placed 2 years ago for high grade atrioventricular block. The temperature on admission was $35.6^{\circ} \mathrm{C}$. Clinical examination was otherwise unremarkable. The white blood cell count was $1510^{9} / 1$, platelet count $4010^{9} / 1$ and the C-Reactive Protein (CRP) concentration $109 \mathrm{mg} / \mathrm{l}$. A whole body CT scan did not find any lesion but transthoracic echocardiography revealed a hyperechogenic mass floating in the right ventricle. Three samples were collected for blood culture but remained sterile. After 7 days, the patient left the hospital against medical advice.

Four days later he was admitted in our institution with delirium. His temperature was $35.4^{\circ} \mathrm{C}$ and he had a macular scattered purpuric eruption over the arms, legs and trunk. CRP was still high at $137 \mathrm{mg} / \mathrm{l}$ and white blood cell count at $1110^{9} / \mathrm{l}$, platelet count was stable at $3910^{9} / 1$ and there was no disseminated intravascular coagulation. Bone marrow aspiration showed a normal number of megakaryocytes. A whole body CT scan was provisionally interpreted as normal except for several unremarkable pulmonary micronodules. The spinal fluid was normal.

In the next days, the purpura became palpable. One among six blood cultures revealed a Gram positive anaerobic bacillus at 93 hours of incubation, which was identified as P. acnes. The micronodules on chest CT were reinterpreted as septic pulmonary embolism. The skin 
biopsy was also compatible with cutaneous septic embolisms. Transthoracic and transoesophageal echocardiography confirmed a large echogenic mass of $6 \times 3 \mathrm{~cm}$ surrounding the lead of the pacemaker in the right atrium and prolapsing in the right ventricle during diastole (Figure 1A, Movies 1 and 2).

Still unsure if the $P$. acnes was the culprit or a skin contaminant, an antibiotic regimen active against $P$. acnes but also staphylococcal species was commenced (amoxicillin $12 \mathrm{~g}+$ clavulanic acid $600 \mathrm{mg}+$ gentamicin $180 \mathrm{mg}$ a day). The patient underwent cardiac surgery to remove the pacemaker with the vegetation on its leads (Figure 1B). The tricuspid valve was replaced by a biological prosthesis because of a perivalvular abcess found intraoperatively. An epicardial pace-maker was placed. Microscopy and culture of the vegetation were negative, but the 16S rRNA gene PCR amplification confirmed the presence of $P$. acnes. Antibiotics were changed for amoxicillin $12 \mathrm{~g}+$ rifampicin $1200 \mathrm{mg}$ a day for 6 weeks. Five days after surgery, the platelet count increased to $30010^{9} / 1$ and the purpura disappeared. The three blood cultures drawn at the first hospital and the five other blood culture drawn at our hospital before antibiotics onset remained sterile at four weeks.

\section{DISCUSSION}

Cardiovascular implantable electronic device (CIED) infections have been the subject of a recent scientific statement by the American Heart Association. ${ }^{3}$ CIED implantation rates, especially permanent pacemaker, have strongly increased over the past years and devices are more frequently placed in elderly and frail patients, ${ }^{4}$ explaining higher rates of CIED infections. Pocket infections with or without associated bloodstream infection are more frequent than definite device infection (endocarditis). A recent study evaluated the rate of device-related endocarditis at 1.9/1000 device-years. ${ }^{5}$ The main risk factors of devicerelated endocarditis are immunomodulatory therapy, chronic corticosteroid use, hemodialysis and presence of remote focus of primary infection. ${ }^{6}$ About one third of devicerelated endocarditis occur more than 1 year after the last implantation procedure; clinical and microbiological features are similar in early- and late-onset endocarditis, with staphylococcal species causing up to $90 \%$ of cases. ${ }^{7}$ Although device-related endocarditis may present without fever, biological markers of inflammation are almost always elevated. ${ }^{7}$ As in rightsided endocarditis, pulmonary abnormalities are a clue to the diagnosis. The two most useful 
diagnostic tests are blood cultures and transesophageal echocardiography, both with a sensitivity of 90 to $95 \%{ }^{3,7}$ Patients with suspected CIED should therefore have at least 2 sets of blood cultures before antibiotherapy is commenced. ${ }^{3}$ However, falsely positive hemocultures due to skin contaminants are a well known issue and as much as $70 \%$ of leadassociated masses are non-infectious incidental findings. ${ }^{8}$ Appropriate antibiotherapy and device removal are both indicated when device-related endocarditis is diagnosed. ${ }^{3}$

A recent review reports 58 detailed cases of endocarditis due to Propionibacterium species, including three associated to pacemakers. ${ }^{2}$ This disease may be underdiagnosed and underreported because Propionibacterium species are often disregarded as skin contaminants when isolated in blood cultures and are sensible to empirical therapy with betalactams or glycopeptides. In this series, endocarditis due to Propionibacterium species involved a prosthetic valve in $67 \%$, a permanent pacemaker or defibrillator in $7 \%$ and another prosthetic device in $5 \%$ of cases. The median delay between valvular replacement or device insertion and endocarditis was 4 years. Propionibacterium species are able to cause late post operative prosthetic valve endocarditis due to their ability to adhere to foreign body surfaces and produce a biofilm. ${ }^{9,10}$ They are low virulence bacteria, associated with minimal clinical and biological signs of infection. Their growth is slow and median time to positive blood or valve culture is 7 days (range 4-14); blood culture remain negative in almost $40 \%$ of cases. $^{2}$ Much of the antimicrobial regimen choices are extrapolated from in vitro or in vivo models of foreign body infections. Six weeks of a penicillin associated with a non-betalactam antibiotic should be prescribed. Aminoglycosids are possible choices but rifampicin and linezolid is increasingly used to take advantage of their biofilm penetrating ability. ${ }^{11,12}$ Second or third generation cephalosporins may be used in patients with reported penicillin allergy without severe or anaphylactic reactions; ${ }^{13}$ combining rifampicin with linezolid is another option. $^{12}$

\section{CONCLUSION}

Although uncommon, the diagnosis of Propionibacterium endocarditis should be considered when isolated in blood cultures even if the delay to positive culture is long and if only a few bottles are positive. The index of suspicion should be especially high in patients carrying a prosthetic valve or an implantable electronic device. 


\section{References}

1. Jakab E, Zbinden R, Gubler J, Ruef C, von Graevenitz A, Krause M. Severe infections caused by Propionibacterium acnes: an underestimated pathogen in late postoperative infections. Yale J Biol Med. 1996;69:477-82.

2. Sohail MR, Gray AL, Baddour LM, Tleyjeh IM, Virk A. Infective endocarditis due to Propionibacterium species. Clin Microbiol Infect. 2009;15:387-94.

3. Baddour LM, Epstein AE, Erickson CC, Knight BP, Levison ME, Lockhart PB, et al. Update on cardiovascular implantable electronic device infections and their management: a scientific statement from the American Heart Association. Circulation. 2010;121:458-77.

4. Zhan C, Baine WB, Sedrakyan A, Steiner C. Cardiac device implantation in theUnited States from 1997 through 2004: a population-based analysis. J Gen Intern Med. 2008;23 Suppl 1:13-9.

5. Uslan DZ, Sohail MR, St Sauver JL, Friedman PA, Hayes DL, Stoner SM, et al. Permanent pacemaker and implantable cardioverter defibrillator infection: a populationbased study. Arch Intern Med. 2007;167:669-75.

6. Le KY, Sohail MR, Friedman PA, Uslan DZ, Cha SS, Hayes DL, et al. Clinical predictors of cardiovascular implantable electronic device-related infective endocarditis. Pacing Clin Electrophysiol. 2011;34:450-9.

7. Massoure PL, Reuter S, Lafitte S, Laborderie J, Bordachard P, Clementy J, et al. Pacemaker endocarditis: clinical features and management of 60 consecutive cases. Pacing Clin Electrophysiol. 2007;30:12-9.

8. Downey BC, Juselius WE, Pandian NG, Estes NA 3rd, Link MS. Incidence and significance of pacemaker and implantable cardioverter-defibrillator lead masses discovered during transesophageal echocardiography. Pacing Clin Electrophysiol. 2011;34:679-83.

9. Guío L, Sarriá C, Sala M, Sánchez Madrid F, McDowell A, et al. Demonstration of biofilm in vitro propionibacterium acnes prosthetic valve endocarditis. Clin Res Cardiol. 2007;96:446-7. 
10. Ramage G, Tunney MM, Patrick S, Gorman SP, Nixon JR. Formation of Propionibacterium acnes biofilms on orthopaedic biomaterials and their susceptibility to antimicrobials. Biomaterials. 2003;24:3221-7.

11. Furustrand Tafin U, Corvec S, Betrisey B, Zimmerli W, Trampuz A. Role of Rifampin against Propionibacterium acnes Biofilm In Vitro and in an Experimental Foreign-Body Infection Model. Antimicrob Agents Chemother. 2012;56:1885-91.

12. Bayston R, Nuradeen B, Ashraf W, Freeman BJ. Antibiotics for the eradication of Propionibacterium acnes biofilms in surgical infection. J Antimicrob Chemother. 2007;60:1298-301.

13. Pichichero ME, Casey JR. Safe use of selected cephalosporins in penicillin-allergic patients: a meta-analysis. Otolaryngol Head Neck Surg. 2007;136:340-7. 
Figure 1. A. Transesophageal echo $\left(20^{\circ}\right)$ showing a large echogenic mass surrounding the leads of the pacemaker in the right atrium (arrow). RA: right atrium, RV: right ventricle, LA: left atrium, LV: left ventricle. B. 6 × $3 \mathrm{~cm}$ vegetation on the pacemaker leads.

Movie 1: 2D Transesophageal echo $\left(20^{\circ}\right)$ showing a large echogenic mass surrounding the lead of the pacemaker in the right atrium and prolapsed largely in diastole in the right ventricle

Movie 2: 3D Transesophageal echo $\left(20^{\circ}\right)$ showing a large echogenic mass surrounding the lead of the pacemaker in the right atrium and prolapsed largely in diastole in the right ventricle 
A
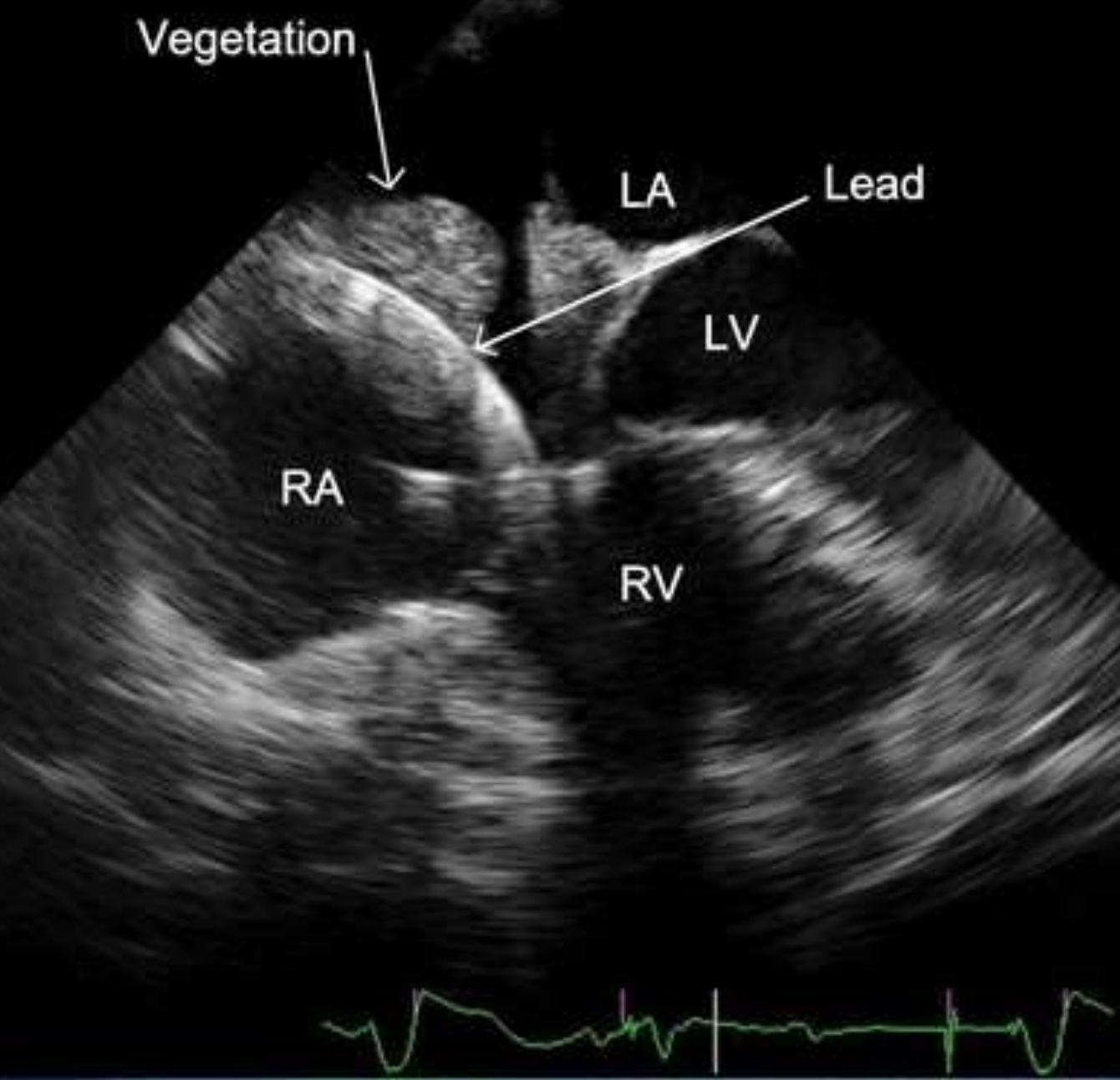

B

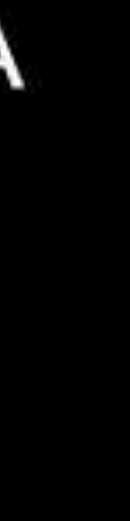

DERMOTRACE

(8)

C 6 movernosis.

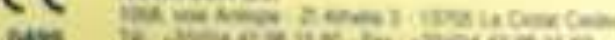

(1).

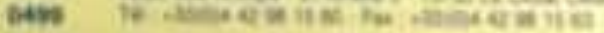

